\title{
CONTROLE ESTATÍSTICO DE PROCESSO APLICADO AS OPERAÇÕES DE PREPARO DE SOLO PARA MUDAS DE CACAU
}

\author{
AUTOR: HIAGO SILVA DOS SANTOS \\ CO-AUTOR/ORIENTADOR: RAFAEL HENRIQUE DE FREITAS NORONHA
}

Resumo: O preparo de solo é uma das etapas fundamentais para a implantação de uma lavoura de cacau, levando em consideração que as operações mecanizadas tende a ser uma etapa na qual busca-se a melhor efetivação dentro dos conjuntos de técnicas que buscam avaliar, melhorar e as operações agrícolas. Objetivou-se avaliar, identificar e adequar a qualidade das operações de preparo de solo para implantação da lavoura cacaueira por meio de cartas de controle com a utilização de Roçadora, Arado, Grade e Sulcador. A pesquisa foi realizada em uma área experimental da CEPLAC (Comissão Executiva de Plantadores de Cacau) no município de llhéus, na Bahia, entre o período de agosto de 2019 e junho de 2020. A qualidade das operações de preparo de solo para implantação do cacau por meio de cartas de controle apresentou estabilidade de processo nas operações de roçagem, aração, gradagem e sulcação para velocidade de trabalho, mesmo diante da variabilidade espacial do relevo. As cartas de controle apresentaram comportamento instáveis para o consumo de combustível para as operações de roçagem e gradagem, possibilitando a identificação das causas especiais para maior consumo proporcionando maior assertividade na implantação de uma lavoura cacaueira.

Palavras-chave: Qualidade, Cartas de Controle, Theobroma cacao L. 